\title{
TEXTURE OF MAGNETITE OBSERVED DURING THE PHASE TRANSFORMATION HEMATITE MAGNETITE.
}

\section{by : MODARESSI A. AHRA E.H. HEIZMANN J.J.}

Laboratoire de métallurgie physique et chimique, Université de Metz Ile du Saulcy, 57045 Metz Cedex (France)

During most chemical reactions there is a crystallographic phase transformation, which very often are linked by structural relationships(1-3)

Several orientations between magnetite and hematite, have been already observed. Now at least 8 different orientations are known (3 - 7).

Recently we have observed two new ones named $\mathrm{H}$ and $\mathrm{K}$. Their structural relationships are respectively $(001)_{\mathrm{M}} / /(001)_{\mathrm{H}}$ with ${ }^{[110]_{M} / /[10.0]^{*}}{ }_{\mathrm{H}}$ and $(332)_{M} / /(001)_{\mathrm{H}}$ with $[110]_{\mathrm{M}} / /[10.0]^{*}{ }_{\mathrm{H}}$

These orientations depend on the temperature of reduction of hematite and their location in the magnetite layer. The multiplicity of these orientation can be explained in terms of the crystallographic symmetries of hematite $3 \mathrm{~m}$ and magnetite $\mathrm{m} 3 \mathrm{~m}$.(8).

When hematite is reduced into magnetite the behaviour of the reactions is topochemical i,e the interface remains parallel to the out side surface of the sample (9). In spite of these observations the phase transformation is not a topotactical one, because the orientations between hematite and magnetite are not the same in all the volume of hematite which is reduced.

In this study we want to linked the scanning electron microscope observation to the orientations evolutions of magnetite layer. These orientations were determined by texture goniometry. 
These linkage could explain the cracks in the magnetite layer which are benefic for the reduction rate but undesirable for the mechanical properties of the load iron ores in the reducing reactors.

\section{EXPERIMENTAL STUDY}

We have chosen single crystals of Itabira hematite, with well developped (00.1) faces. These crystals are reduced by carbon monoxyde and dioxyde mixture at $950^{\circ} \mathrm{C}$. After $30 \%$ of reduction rate the crystals are quenched in Nitrogene atmosphere at room temperature; for this quenching the reduced crystal is dropped down in the cold part of the vertical furnace.

Among the reduced crystals we have chosen the crystal of which one of the reduced (001) face was partially broken in a parallel direction to the outside surface. Figure (1).The broken part II corresponds only to the magnetite layer. On this crystal we have made numerous scanning electron observations and pole figures.

The magnetite layer is about $450 \mu \mathrm{m}$ thick. The different pictures wich have been made on the sample are labelled on the figure (1) by numbers depending on their location. In the same way the pole figures are also labelled by small letters.

Among all the pole figures and pictures, we present only these which are caracteristics and useful for the understanding.

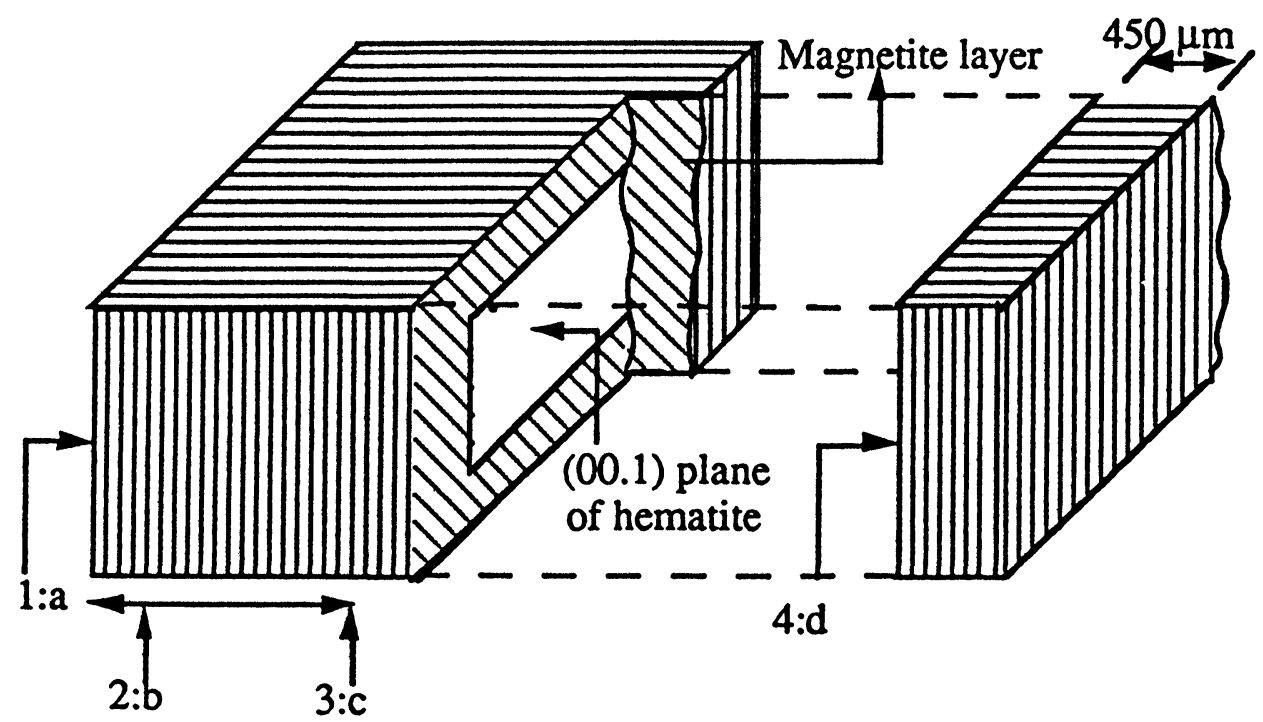

Figure 1 Hematite crystal reduced in magnetite the crystal of wich one of the reduced (001) face was partially broken in a parallel direction to the outside surface . the broken part II correspond only to the magnetite layer . 


\section{POLE FIGURES AND SCANNING OBSERVATIONS}

All the (220) pole figures were measured with the same geometrical arrangement and the same steps of measurement. So the whole intensity of each pole figure is approximatively the same within a range of $5 \%$.

All the pole figure presented on the figure 2 are in a normalized scale, so in this case they can be compared.

To observe the orientations between the surface and the interface, successive layers of magnetite are removed by polishing.

On the surface of the sample the pole figure shows a well oriented magnetite.figure (2-a) Its orientation is only the A orientation $(111)_{\mathrm{M}} / /(00.1)_{\mathrm{H}}$ with [110] $\mathrm{M} / /[10.0]^{*}{ }_{\mathrm{H}}$ and its crystallographic equivalent.

After a removing of solely $20 \mu \mathrm{m}$ of magnetite one obtains one other kind of orientation named $\mathrm{K}$ with a multiplicity of 6 figure (2-b)

Between $100 \mu \mathrm{m}$ and about $20 \mu \mathrm{m}$ in front of the interface, the $\mathrm{N}$ orientations (9710) // (00.1) with [0 107] / [10 0 ${ }^{*}$ are found. The multiplicity of $\mathrm{N}$ is 12 figure (2-c).

The $\mathrm{K}$ and $\mathrm{N}$ orientations are very close together. Near the interface we observe the $A$ orientations and the $(10.4)$ poles of the underlying hematite.

The peaks of this A orientation are extremely sharp like those of a single crystal.

If we start from the interface where takes place the chemical reaction, towards the surface.Figure (2-d). One could say that : the magnetite wich is newly formed is perfectly oriented then it splits in twelve orientations (N). These orientations are then regrouped in 6 orientations which finally give the two $\mathrm{A}$ orientations.

The scanning observations confirm this textural evolution.Figure (3Pictures).

Picture 1 represents a cross section of the magnetite layer starting at the surface.

Picture 2 shows the magnetite layer

Picture 3 shows the magnetite layer near the interface

On picture 4 magnetite layer is seen in a perpendicular direction to the $(00.1)_{\mathrm{H}}$ plane of hematite. On picture 1 there are two areas :

Untill 10 to $20 \mu \mathrm{m}$ under the surface the cracks of the magnetite are perpendicular to the surface corresponding to the A orientations.

After this first layers Picture 2, we observe small sticks of magnetite with some micrometer thick- generally longuer than $100 \mu \mathrm{m}$ The cracks between the sticks of $(0,5 \mu \mathrm{m})$ wide made an angle of $10^{\circ}$ with the normal 

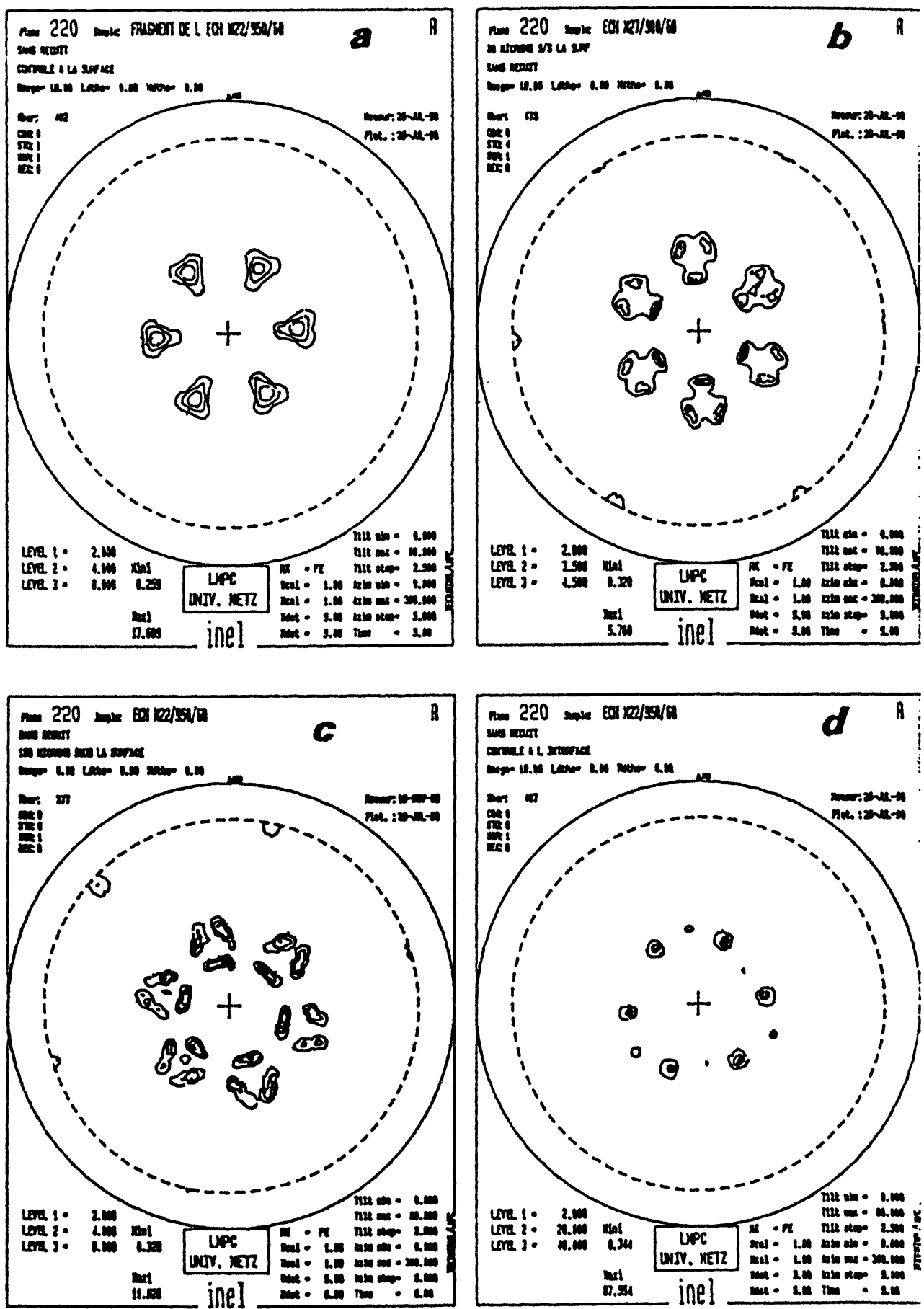

Figure 2 Pole figure of magnetite ( 220 )

Development of the magnetite crystallographic texture between the outside surface and inetrface. 


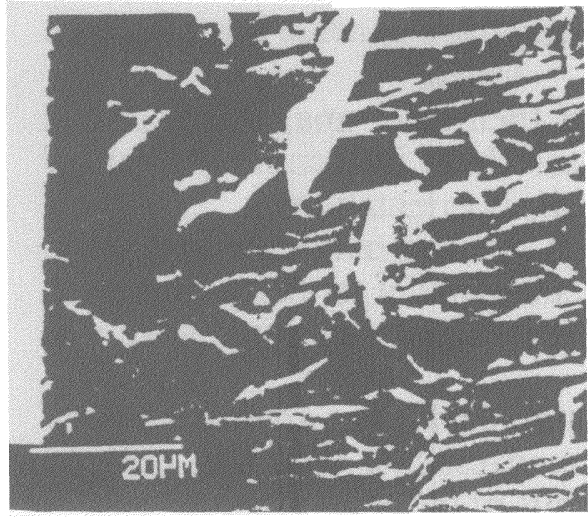

1

3

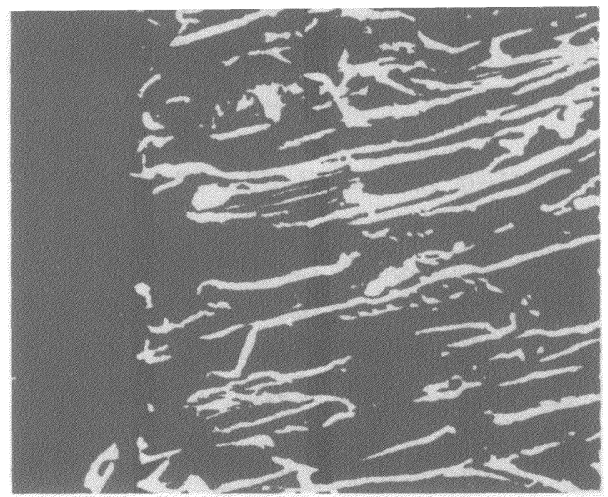

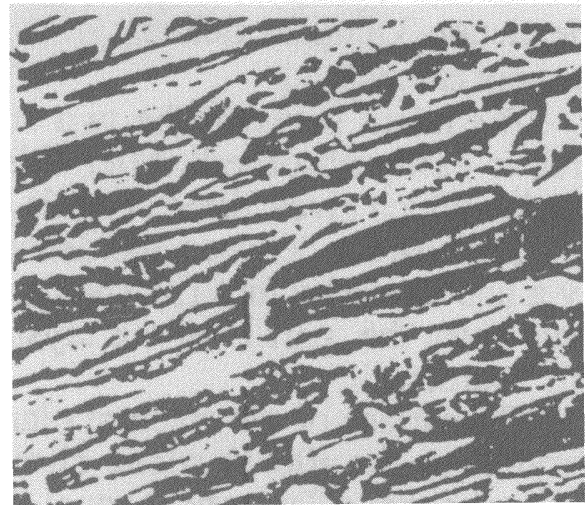

2

4

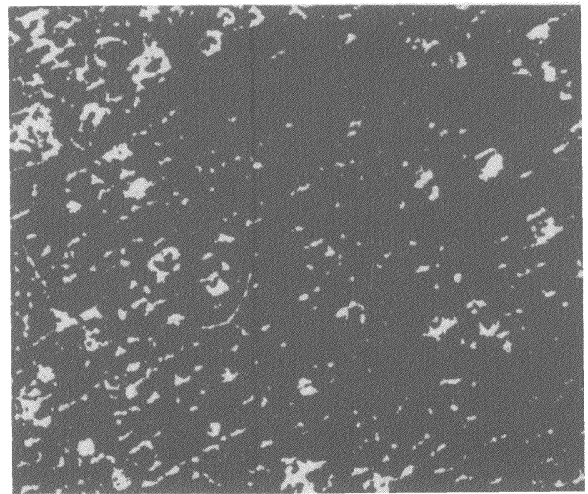

Figure 3. Pictures

Scanning electron microscopy

Development of the magnetite crystallographic texture between the outside surface and inetrface 
to surface, this angle corresponds to the angular deviations between $A$ and $\mathrm{K}$ or $\mathrm{A}$ and $\mathrm{N}$ orientations .From the interface, located on the right part of the picture 3. untill a tickness of, 5 to $10 \mu \mathrm{m}$ the magnetite layer is dense without cracks.

The misfit between the two structures (hematite -magnetite) in this area is easily absorbed. After this tickness there is a comming out of cracks. Which gives tilted crystals having the $\mathrm{N}$ orientations.

The boarder between the dense and the cracked magnetite is marked by a line on the picture (3).The fracture plane parallel to the surface wich have given the part II of the crystal have taken place approximatively at this boarder.

The surface of the fracture plane, picture 4, which is approximatively parallel to the $(00.1)$ plane shows latticed cracks. One can noticed numerous triangular or hexagonal shaped cells of the cracks lattice.

The cracks wich separate each small sticks of magnetite from each other should be $(h+k+1)=0$ lattice planes of magnetite and propably (11.0) planes.

\section{CONCLUSIONS}

Structural study of the magnetite layer, linked with scanning observation allows us to have important informations concerning the chemical behaviour of the phase transformation hematite - magnetite. The different orientations observed by texture goniometry, allowed us to analyse with more precision the scanning electron micrograph.

The magnetite is porous enough allowing the reducing gaz to reach the reacting interface.

The pores are channels boarded by $(h+k+1)=0$ faces of magnetite.

Very close to the interface exist a dense magnetite which must be a protective layer against the reducing gaz. Never the less the reaction may progress by solid state diffusion of iron through this layer of dense magnetite.

At the surface the reorganized of magnetite is due to the sintering.

1 - F.K.Lotgering and E.W.Crocter, J. Inorg. Nucl. Chem/ (1959) 113

2 - H.R. Oswald and J.R. Gunter, J .Solid. State. Chem/ 13 (1975) 330

3 - J.J Heizmann P. Becker and R. Baro, Mém. Sci. Rev.72 (1975) 285

4 - P. Becker, J.J. Heizmann and R. Baro J. Appl. Cryst. 10 ( 1977 ) 77

5 - L. Bursil and R. Withres, J. Appl. Cryst. 12 ( 1979 ) 287

6 - R. Withers and L.Bursil, J. Appl. Cryst. 93 (1980) 346

7 -J.J Heizmann, H El-Abdouni, A. Vadon, C.Laruelle ICOTOM-8 -795.

8 -A. Modaressi H. El Abdouni J.J Heizmann, React.Solids, 7 (1989) 19

9 - A. Modaressi H. El Abdouni and J.J Heizmann Mém. Sci. Rev. Métall. ; janvier ( 1990 ) 13. 